Review article

\title{
The effects of premarital relationship enrichment programs on marriage strength: A narrative review article
}

\author{
Zohreh Shahhosseini $^{1}$, Zeinab Hamzehgardeshi ${ }^{1}$, Maryam Kardan Souraki ${ }^{12^{2 *}}$
}

(Received: 23 Aug 2014; Accepted: 5 Nov 2014)

\begin{abstract}
Background and Purpose: Strengthening marriage relationship includes a body of programs focusing on boosting the couples' common understanding, honesty, trust, empathy and coordination. Premarital consultation along with the couples' relationship enrichment can result in their improved relationship. The current study aims to analyze the studies conducted on consultation programs for marriage relationship enrichment and marriage strength.

Methods: The current study is a narrative review performed using key words related to advanced search in database like Pubmed, Google Scholar, Web of Sciences, Magiran, Iran Medex and SID in the past 20 years. After recovering 57 papers, 10 Persian ones along with 25 English papers directly related to this issue and cited by famous authors many times have been given in the paper's results.

Results: The findings show that premarital consultation through promoting life skills, familiarity with spouse selection criteria and paving the ground for accepting gender role in marriage can be considered as one of the critical components of strengthening marriage.

Conclusion: Premarital consultation helps human beings to improve their relationship by knowing themselves and their would-be partner, clarifying their expectations from each other, promoting problem solving and getting aware of compatible and incompatible characteristics before marriage. By considering the population policy of Iran and in order to meeting favorite relationship between newly wedding couples, it's suggested to provide suitable premarital counseling packages according to Iranian socio-cultural context.
\end{abstract}

Keywords: Marriage, Premarital consultation, Marriage strength

\section{Introduction}

Family is a social system consisting of a group of people living with one another via marriage, reproduction and children rearing and plays a vital role for the individuals 'growth, progress and socialization (1). In this respect, it can be stated that marriage is one of the most complicated human relationships on which family foundation is based and has been analyzed as an absolutely general phenomenon in the social life of all communities (2). Marriage is to enter a new stage of life encompassing a very important part of individual and social life of each person. Besides, marriage is the factor behind family genesis, reproduction and survival of human generation and if it is done according to the required conditions and sufficient knowledge, it can have significant effects on the health of the people and society. In a successful marriage, diseases and be increase $(2,3)$. How to start and how to form couples' relationship can influence them and their children positively or

\footnotetext{
${ }^{1}$ Department of Midwifery and Reproductive Health, Nasibeh Nursing and Midwifery faculty, Mazandaran University of Medical Sciences, Sari, Iran.

${ }^{2}$ Student Research Committee, Mazandaran University of Medical Sciences, Sari, Iran.

*Corresponding author: Maryam Kardan, Department of Midwifery and reproductive health, Nasibeh Nursing and Midwifery faculty, Mazandaran University of Medical Sciences, Sari, Iran, E-Mail: maryam_kardan@yahoo.com.
} 
negatively. Thus it seems imperative for creating successful marriage it's necessary to make the youth more prepared and knowledgeable since in addition to facilities, prosperous marriage requires certain skills and capabilities (4).

In the psychologists' mind, a person is ready to marry when she/he possess sufficient social maturity, motivation and information $(5,6)$. Premarital consultation is an interventional procedure for the couples on the verge of marriage with the goal to train the necessary skills and in order to improve their relationship (7). This program contains preventive aspect and its goal is a successful marriage and also boosting the couples to maintain and keep their function in the maximum level $(8,9)$. Benefitting from premarital consultation services makes the man and woman start their shared life with more awareness and equipped with enough knowledge in their relationship and their would-be spouse and also the significance and goals of marriage (7).

The first premarital consultation was done in 1924 by Ernest Groves for the families living in Boston University (8). In Iran, the premarital training plan was ratified in 1991. In this way authorities of marriage registry offices were obliged to announce marriage bond of the ones on the verge of marriage only if the parties presented health certificate based on the examinations and passing training course (10). The objective to implement this plan is to promote the couples' awareness about the importance and necessity behind the relevant issues of pregnancy health, prevention of the maladies especially venereal diseases, genetic ones and familiarity with health-treatment services providing units (11).

Premarital consultation can happen widely through the knowledge about marriage goals, the women's and man's psychological knowing, being aware of correct marriage criteria and having the necessary conditions to uptake marriage and sex education (12). Since premarital consultation is one of the suitable ways to maintain and protect families and its preventive aspects are more important than its treatment aspects, thus the researcher's goal to do this review study has been to categorize the findings of the papers dealing with analyzing the effect of marriage strength enrichment consultation programs, so that via this path and recognizing the significance of premarital consultation service in family basis strength and successful marriage, it is possible to help society premarital consultation service.

\section{Materials and Methods}

The current research is a narrative review conducted using key words related to advanced search in database like Pubmed, Google Scholar, Web of Sciences, Magiran, Iran Medex and SID in the past 20 years. After recovering 57 papers, 10 Persian ones along with 25 English papers directly related to this issue and cited by famous authors many times have been given in the paper's results. The ethical considerations have been pursued by loyalty to literature translation, lack of committing plagiarism in the literature and the spiritual ownership right in exploiting the obtained information.

\section{Results}

Based on the findings, the significance of premarital consultation programs on strengthening couples' relationship can be summarized in three main axes depicted in diagram 1.

1) Life Skills Promotion: Life skills refer to a collection of mental and social capabilities increasing the individual's compatibility and positive behavior. These skills make people take on their social role related responsibilities and free from any harm to themselves and others, encounter life problems and make their own choices and have appealing behaviors throughout their lives (13). Training life skills as the important and key element in individuals' life has been set forth worldwide.

Various studies have indicated that the capabilities an individual acquires in these trainings 
enable him/her to value life opportunities and get prepared to cope with probable dangers (14-18). Also training life skill raises mental and social capabilities and helps the person to face life situations effectively and to adaptively function with other humans, society, culture and the environment and provide their mental health. In addition, this process can enhance the ability to manage life, to recognize emotions, feelings and needs of their own and of the other ones and increase marital satisfaction and compatibility (14-16). Reviewing the existing studies implies that training some of these life skills in the couple counseling sessions can assist them to maintain and promote their life quality.

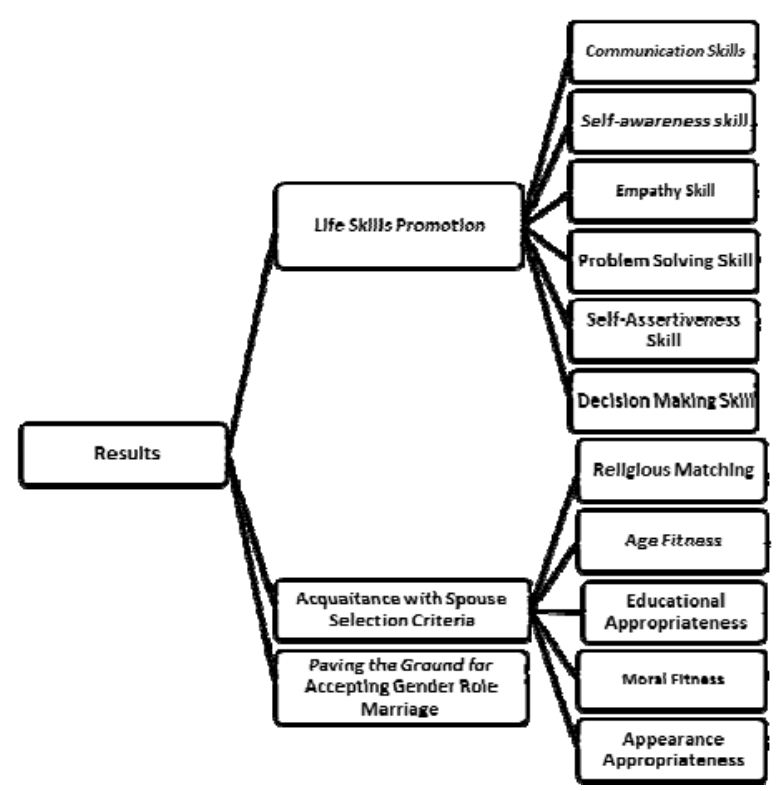

Diagram 1. Main findings towards the effects of premarital relationship enrichment programs on marriage strength.

1-1) Communication Skills: Communication skills are of the types that when the spouses learn, they can improve their relationships (4). Training Communication skill aims to help the couples to form and boost their marital health and stability and relationships (17). It's suggested that the best solution to raise marital contentment in couples is to use social norms, satisfaction with the relationships and flexibility in their desires (18). The skillful relational process between a couple leads to the most satisfactory and effective outcome between them. The spouses who participate in couple training programs mentioned their positive effects as : better understanding of their own and that of their spouse, feeling more valuable, settling disputes better and faster, enjoying each other's company more, new ways to express closeness and the relational potential and ultimately marriage satisfaction increase $(1,3,4)$. Also it's reported that marriage satisfaction increases as communication skills are promoted. In this way marital satisfaction level increases in men more than women (19).

1-2) Self-awareness skill: Self-awareness includes identifying all psychological, social, emotional and physical dimensions of the individuals. The more one gets to know themselves, the more probable it is to develop independence and self-confidence and paves the ground for better growth $(20,21)$. In fact, a person's self-awareness helps acquire skills such as decision making, recognize emotions and master behaviors through better knowing their needs and characteristics and enables the one to be more realistic when tackling their strong and weak points and face nuisances in life more effectively (22). On the other hand, the first step to select spouse is the person's information about himself/herself. The answer to the question as (who should I marry to?) that people wonder depends on recognizing self. Also self-awareness plays the key role in life determining decision makings and the person's compatibility and controlling emotions and has a significant impact on stress coping styles. Through the knowledge people have about each other, they can understand others better and accurately predict others' behaviors. Thus self-awareness causes the self-conscious person to experience fewer problems in order to have more effective role in their interpersonal relationships with others to strengthen marital relationships (21, 23).

1-3) Empathy Skill: Empathy is an essential element for successful interpersonal performances. In fact, empathy is the ability to experience other 
one's emotions and allows the person to harmonize him or herself to what others think of him/her, to communicate with their surroundings and to avoid harming other ones $(24,25)$. It's showed that increased empathy helps to lower couple's behavioral disorders and improve their interpersonal relationships (26).

1-4) Problem Solving Skill: Problem solving is of the basic life skills and of the effective tools to cope with many difficulties and as a result, to maintain and enhance the person's personal coherence (27). Problem solving refers to cognitive-behavioralinnovative process by which the person determines compatible effective coping strategies for daily nuisances (28). On the one hand, problem solving skill depends on the individuals' cognitivebehavioral capability so that the more accurate the individuals' emotional reaction to the problems, the more their problem solving gets due to more knowledge about the problem and the better their interpretation of the situation and the less their being influenced by stress (27). Problem solving skill helps the couple to analyze problem solving solutions and achieve more cooperation and empathy so that their agreement goes up. In other words, problem solving skill assists the couple to collectively solve their problems rather than having dispute, criticism and reproach .That in its turn, it is one of the most significant factors in raising the couple's agreement and intimacy $(29,30)$.

1-5) Self-Assertiveness Skill: Self-assertiveness is of the most critical and fundamental social skills being significant in establishing, keeping and promoting interpersonal relationships. Selfassertion means to express beliefs, emotions and thoughts so that it hinders disrespecting and violating others' rights $(21,28)$. Literally, selfassertion is one of the life skills to raise selfesteem, express thoughts and emotions logically, decrease anxiety, enhance relational and social skills and also observe others' rights and at the same time, adjudicate their rights and finally, increase contentment and happiness in life (30).
One of the most fruitful methods for self-assertion is using verbal message consisting of three parts as non-judgmental description of the behavior requiring change, venting emotions of the person simultaneously with self-assertion and clarifying objective or tangible effect of the other party's behavior on the person while asserting.

1-6) Decision Making Skill: In decision making skill, people learn how to decide logically and correctly, to assert and set forth their ideas and give decisive response to others' demands. In premarital counseling process, the couple is helped to identify the possible solutions, to evaluate the results multidimensionality and finally, to select the best and the most optimal solution when facing life special conditions for sensible decision making (31, 32).

2) Acquaitance with Spouse Selection Criteria: Marriage is considered as the first and the most critical family life cycle and the most important factor to create healthy society and viewed as very significant phenomenon. Among this, the issue as spouse selection as the primary cornerstone of family formation is highly important and in fact, all emotions, reproduction process, future generation fostering, needs supply responsibility and future challenges of our life depend on it $(33,34)$. In addition to increasing the couple compatibility probability, familiarity with the criteria for selecting the would-be spouse during counseling sessions can highly prevent from choosing spouse by accident and its due challenges. In this respect, the existing studies point out some of the cases of optimal matching for the couples on the verge of marriage as the effective ones in successful marriage:

2-1) Religious Matching: There is a positive meaningful relationship between religion and marital satisfaction (35). It seems that this sort of conformity between a couple and mechanisms such as not being disloyal in marriage, spouse support increase, sharing original religious values and participating in religious activities at home may raise happy marriage (36). It's revealed that a 
significant relationship exists between religious attitude and its subscales and marriage satisfaction (37). Islam also considers religious similarity as the prerequisite for permanent marriage happening and forbids Muslims from marriage bond with nonMuslims. Also Islam views a pious man peer for a pious woman and a Muslim man as the match for Muslim woman.

2-2) Age Fitness: Appropriate age for marriage differs in various geographic and climatic conditions. The acceptable age difference between spouses is 2-5 years (6). It's suggested that increased contentment is seen in the couples with less age difference and the maximum satisfaction has been stated by those having less than 5 years age difference with their spouses. High age difference results in creating various physical, emotional and social gaps for each of them and limiting the individuals' emotional intimacy and cooperation with each other and decreasing their marriage satisfaction (38). Besides, it has been reiterated that in the couples with high age difference, there is lowered marriage contentment so that despite being old, men marry to young women and adopt patriarchal relations in their marriage (39).

2-3) Educational Appropriateness: The studies have implied that there is a direct relationship between marriage satisfaction and the couple's educational similarity. In this relationship, it has been shown that despite boys, girls are more willing to select husband with higher education (40).

2-4) Moral Fitness: In a research with the goal to determine spouse selection criteria from medical sciences university students' perspective it's indicated that the students in both genders consider moral aspect as the key for spouse selection (41).

2-5) Appearance Appropriateness: Many factors play role in marriage success and satisfaction like partners' personality trait, mutual understanding, thinking maturity, mental balance, economic factors, sexual contentment and love and interest as the most important factors generating a pleasing and happy life (42). In this respect, it's implied that boys have taken biologic criteria including: physical health, appearance and attraction of the considered person as significant while girls have viewed psychological and social criteria involving social behaviors, decision making power, education, religious and cultural congruence important in selecting spouse (34).

3) Paving the Ground for Accepting Gender Role Marriage: Gender role is a set of social norms based on which a gender behaves in society (41). Accordingly, premarital health counseling plan can be one of the important services in this period since it helps to get fully knowledgeable about significant health issues in fertility and establish their sexual relationships accurately. The researchers assume that premarital teachings for the youth in all communities can have remarkable impact on reproductive and sexual health behaviors and their management and training seems a must. It seems premarital counseling helps to recognize personal risk factors and personal flexibility aspects and the couple gets ready for marriage .So that the couples who have received premarital training are less probable to get separated (12). Moreover, it has been suggested that the couple sexual training affects creating a more contented and stable life (43).

In a healthy marriage, the existence of a favorable sexual relationship causes the partners' contentment and has a great role in family circle success and stability (44-46). The studies have demonstrated that lack of correct information, poor inter couple skills and expectations and unrealistic function in marriage relationship between the couple play a remarkable role in generating sexual problems (47). Despite all sexual tendencies being natural and involuntary, sexual attitude and behaviors can be learned, as knowledge goes up, the individual will be able to move towards healthier sexual relationships. As the couples get more knowledge in sexual matters and modify their unrealistic 
expectations, empowering programs in marriage increases marriage life happiness and satisfaction
(48-50). A summary of the related papers and their results have been given in table 1 .

Table 1. A summary of some studies conducted towards premarital relationship enrichment programs on marriage strength

\begin{tabular}{|c|c|c|c|}
\hline Author & Title & Study type \& Sample size & Intervention \\
\hline $\begin{array}{c}\text { Abbasi } \\
\text { et al.(2011) }\end{array}$ & $\begin{array}{l}\text { The effects of life skills training } \\
\text { on marital satisfaction of } \\
\text { married women: a case study in } \\
\text { dogonbadan, iran }\end{array}$ & $\begin{array}{l}\text { Semi empirical, pretest and } \\
\text { posttest in } 50 \text { married } \\
\text { women }\end{array}$ & $\begin{array}{l}\text { The individuals have been trained } \\
\text { various life skills such as } \\
\text { communication, child rearing and } \\
\text { family pathology and familiarity } \\
\text { with women-man psychology } \\
\text { skills for } 4 \text { days and } 6 \text { h daily. The } \\
\text { participants filled in the } \\
\text { questionnaire once before training } \\
\text { and once a year following training }\end{array}$ \\
\hline $\begin{array}{l}\text { Mehrabizadeh et } \\
\text { al.(2010) }\end{array}$ & $\begin{array}{l}\text { The effectiveness of life skills } \\
\text { training on increase of marital } \\
\text { adjustment in 20-40 year-old } \\
\text { married women }\end{array}$ & $\begin{array}{l}\text { Empirical intervention } \\
\text { (pretest and posttest with } \\
\text { control group ) in } 50 \text { women }\end{array}$ & $\begin{array}{l}\text { Training life skills twice a week } \\
\text { during ten sessions based on life } \\
\text { skills training workbook. After the } \\
\text { training program getting over, both } \\
\text { groups have been taken posttest }\end{array}$ \\
\hline $\begin{array}{l}\text { Yilmaz \& Kalkan } \\
\text { (2010) }\end{array}$ & $\begin{array}{l}\text { The effects of a premarital } \\
\text { relationship enrichment program } \\
\text { on relationship satisfaction }\end{array}$ & $\begin{array}{l}\text { Pretest and posttest } \\
\text { intervention in } 20 \text { persons }\end{array}$ & $\begin{array}{l}2 \mathrm{~h} \text { intervention sessions have been } \\
\text { held for } 7 \text { weeks for intervention } \\
\text { group. After } 7 \text { weeks, both groups } \\
\text { have filled in the questionnaire } \\
\text { again }\end{array}$ \\
\hline
\end{tabular}

Marriage education with

Stelzer (2010) Hispanic couples: Evaluation of communication workshop
Pretest and posttest Workshops on

intervention in 275 couple relationship for 8-16 h.
Training life skills has been effective on marriage enhancement and resulted in women life promotion. The total mean scores of pre-test and post-test has been meaningful.

By training life skills, there is a meaningful difference between the experimental groups subjects and control in terms of marital compatibility.

There is a meaningful difference in the intervention group's posttest score relative to the control group in relational satisfaction and marriage contentment.

Participating in relational workshop has had positive effect on marital satisfaction increase, boosting positive relationship and increasing capability to settle disputes, commitment to the present relationship and reducing negative interaction

Educating relational skills has been effective in boosted marital intimacy in dimensions as emotional, intellectual, social, relational, religious, psychological and sexual intimacy

Educating problem solving skill boosted general intimacy .There is meaningful difference between mean general intimacy of the experimental and control groups

There is a meaningful difference in total score of marriage satisfaction in the experimented men compared with the control group, but the women marriage satisfaction means difference isn't meaningful in the intervention and control groups

\begin{tabular}{|c|c|c|c|c|}
\hline & & & & and control groups \\
\hline $\begin{array}{l}\text { Fathi Moghaddam } \\
\text { et al.(2010) }\end{array}$ & $\begin{array}{l}\text { A comparison of the } \\
\text { effectiveness of communication } \\
\text { skills training for marital } \\
\text { conflicts and quality of life in } \\
\text { female students of Islamic Azad } \\
\text { university, science and research } \\
\text { branch. }\end{array}$ & $\begin{array}{l}\text { Empirical of pretest and } \\
\text { posttest type with control } \\
\text { group in } 32 \text { persons }\end{array}$ & $\begin{array}{l}\text { Two hours sessions where half of } \\
\text { the time has been assigned to skills } \\
\text { education and the other half to } \\
\text { practicing the trained skills. } \\
\text { Practice at home has also been } \\
\text { considered. The taught skills } \\
\text { included the common problems in } \\
\text { family, the communication } \\
\text { barriers, message sending and } \\
\text { receiving skills, effective listening } \\
\text { and speaking, conflict settlement, } \\
\text { self-awareness skills. The posttest } \\
\text { has been completed after the } \\
\text { education sessions getting over }\end{array}$ & $\begin{array}{l}. \text { Educating relational skills lowers } \\
\text { marital conflicts and has positive } \\
\text { impact on life quality. }\end{array}$ \\
\hline
\end{tabular}




\section{Discussion}

Training behavioral skills in marriage helps the individuals to convey their messages more lucidly and effectively; besides, the couples learn how to settle disputes more efficiently than those lacking such skills and they can continue their marriage and solve their marriage conflicts appropriately $(4,14)$. It seems that training life skills using efficient methods like listening, speaking, giving effective non-verbal responses and learning problem solving improves their contentment and relationship quality (47). Some studies conducted in this field suggest that training life skills can have positive effects on family relationships and make emotions such as humanitarianism and charitable behaviors of the participants grow (51).

Since verbal communication is exclusively for humans and individual transfer their attitudes to each other in the form of speech, it seems that training marriage preparedness with the couple communication beliefs changes can reduce irrational communication beliefs (22, 43). Proper communication can raise interpersonal bonds, provide the possibility for more accurate decision, direct the partner's beliefs in reaching further empathy and justify changes and variations. Thus training communication skills is of the most important methods playing role in marriage relationship firmness and survival and in contrast, the most common issue set forth by dissatisfied couples is failure in communication. In this regard, the study performed among Iranian students implies that the highest demand for reproductive health training from the participants' perspective is the requirement of training the suitable behavior with the would-be spouse (52). So that in training programs, it seems this group of individuals has to be included appropriately from school to university level.

According to the results, it can be stated that those marriages are prosperous in which spouse election criteria have been followed correctly and the partners possess the necessary conditions for selection (53). Spouse selection criteria are perceptions about the features claimed from an imaginary mistress or potential spouse and many of such perceptions are explicitly associated with emotions. Sufficient information about one's roles and tasks in marriage helps to start a successful marriage. The couple's knowledge about what brings about marriage communication strength or destruction helps them to be prosperous in marriage (54). Psychologists have stated that in choosing the would-be spouse, there are different ideas about spouse selection criteria $(40,41,55)$ including the following ones. It is vivid that increasing on the verge of marriage couples' knowledge about common ideas on spouse selection can extremely influence choosing the future spouse appropriately and strengthen family base and its survival.

- Accidentalness Idea: Based on this theory, no law exists on spouse selection. Selecting partner like other critical life decisions happens accidentally out of a limited body of individuals generally similar to oneself (54).

- Peer Spouse Idea: According to this idea, spouse selection expected accidentally occurs among the couples being identical physically or psychologically. In reality, people tend to choose those as their spouse who are similar to them. The studies have revealed that similarity, for example, in education means similarity in attitudes, values and beliefs of those who are identical in education, intelligence and religion and have special tendency to create stable relationships in particular marriage $(40,56)$.

- Complementing Idea: To the base of this theory, every person can select a spouse able to compensate their needs and complement each other's weaknesses. The supporters of this theory believe that this is not similarity and consistency rather it is the dissimilarity and inconsistency especially the complementary traits that make individuals marry the other one and maybe for this, extrovert and introvert, domineering and 
dominance-oriented, dependent and caring people are attracted to each other in order to meet their complementary demands $(33,41,56)$.

Although, a happy marriage is partially related to sexual relationship, this relationship may be one of the most critical factors in happiness or lack of happiness. Since if this relationship isn't satisfactory, it may lead to feeling deprivation and frustration, exposing mental health to danger and following it, the family circle breakdown (46).The main problem the present society is facing is lack of sufficient knowledge, lack of correct and fundamental perception of sexual matters, feeling shy to talk about sexual matters, incorrect attitudes and beliefs about this issue among families and especially the newly-weds that is of the effective causes in emerging sexual disorders whose consequence is many families getting ruined $(44,46)$.

In line with this, there are some studies indicating the requirement of training contraceptive methods and healthy marriage relationships during marriage contract as one of the important needs of Iranian youth fertility health. It is obvious that sexual education is a long term process through which the individuals acquire the necessary information and knowledge about sexual matters and form their attitudes, beliefs and values. In order to achieve this goal, it is worth to highlight sexual matters' sociocultural structure and regarding the cultural, social and religious values governing the society, a presentable definition of sexual training has to be presented at various levels. In executing these teachings, considering the individuals position and dignity and the sensitivity of sexual counseling subject by taking the influential obstacles and incentives in presenting reproductive and sexual training and counseling services into account, it is important to execute regular and codified teachings (57).

\section{Conclusion}

The general conclusion is that premarital counseling and training can happen broadly from knowledge about marriage goals, women and man psychological recognition, knowledge about correct marriage criteria to having the required conditions to get into marriage so that the sexual training happens and helps the couple to get fully aware of critical fertility health issues and to establish their sexual relationships correctly. Also this process helps the couple for marriage preparedness by identifying personal risk factors and personal flexibility aspects to create a happier and more stable life. By promoting sexual skills, improving life skills and raising couple's preparedness, premarital counseling can be considered as one of the remarkable components for prosperous marriage. Premarital counseling decreases function disorders and marital problems and also by having enough information and knowledge about themselves and their would-be spouse, it makes the woman and man step into this dynamic and flourishing period more peacefully. Thus it is recommended that given the country governing policies on the importance of population in national authority and taking the current countrywide population dynamism, development and being young as an opportunity and privilege, and in order to offset the population growth rate and fertility rate and families stability and strength and finally, maintain and continue the services provided for the couples on the verge of marriage, we pay particular attention to premarital counseling programs to design native made training and counseling packages based on future field studies consistent with Iranian couples and according to the country governing culture, beliefs and codes.

\section{Conflict of interest}

The authors declare that they have no competing interests.

\section{Author's contributions}

M. Kardan was involved in search and has written the first draft, Z. Shahhosseini and Z. 
Hamzehgardeshi revising the content, and approving the final manuscript as well.

\section{Acknowledgments}

We appreciate research deputy of Mazandaran University of Medical Sciences and Student Research Committee, Mazandaran University of Medical Sciences, Sari, Iran.

\section{References}

1. Abbasi A, Jalilpour N, Kamkar A, Zadehbaghri G, Mohamed F. The effects of life skills training on marital satisfaction of married women: A case study in dogonbadan, Iran. Armaghane-danesh. 2011; 16(6): 587-94.

2. Anderson RT. Marriage: what it is, why it matters, and the consequences of redefining it. Washington,DC: The Heritage Foundation Retrieved October. 2013; 22.

3. Stelzer K. Marriage education with Hispanic couples: Evaluation of a communication workshop. Fam Sci Rev. 2010; 15(2): 1-14.

4. Jafari AR. Analyzing the effectiveness of premarital relational skills on boosting premarital marriage satisfaction. Behavioral Sciences. 2010; 1(2): 31-51.

5. Strong B, Cohen ThF. The marriage and family experience: Intimate relationships in a changing society. Wadsworth:Cengage Learning; 2013.

6. Hadjikhani NA, Hamzeh Gardeshi Z. Maternal and child health. Gorgan: Islamic Azad University of Gorgan; 2012.

7. Murray CE, Murray TL Jr. Solution-focused premarital counseling: helping couples build a vision for their marriage. J Marital Fam Ther. 2004; 30(3): 349-58.

8. Carroll JS, Doherty WJ. Evaluating the effectiveness of premarital prevention programs: a meta-analytic review of outcome research. Family Relations. 2003; 52(2): 105-18.

9. Fathi Moghadam G, Ahadi H, Jamhari F, Fakhri N. A Comparison of the Effectiveness of Communication Skills Training for Marital Conflicts and Quality of Life in Female Students of Islamic Azad University, Science and Research Branch. World J Sport Sci. 2012; 6(1): 73-9.
10. Moodi M, Miri M, Sharifirad GR. The effect of instruction on knowledge and attitude of couples attending pre-marriage consultation classes. J Educ Health Promot. 2013; 2: 52.

11. Moodi M, Sharifzadeh GR. The effect of instruction on knowledge and attitude of couples attending premarriage consultation classes. Journal of Birjand University of Medical Sciences. 2008; 15(3): 32-9.

12. Khaleghinejad K, Abbaspour Z, Afshari P, Attari Y, Rasekh A. Educational needs in premarital counseling: viewpoints of couples referring to health care centers in mashhad. Iranian Journal of Medical Education. 2009; 8(2): 247-52.

13. Rashidinejad M, Miri S, Bahramnejad A. The effect of life skills training workshop on feeling, thinking and behavior of nursing students BAM. Qualitative Research in Health Sciences. 2011; 10(2): 47-53.

14. Mardani Hamoleh M, Rozitalab M. The effect of life skills training on marital satisfaction of hospital female personnel. Psycho-Oncology. 2009; 4(1-2): 1-11.

15. Baghaei-Moghadam G, Malekpour M, Amiri Sh, Molavi $\mathrm{H}$. The effectiveness of life skills training on anxiety, happiness and anger control of adolescence with physical-motor disability. J Beh Sci. 2011; 5(4): 305-10.

16. Pour-Mohseni F, Allah-Yari A, Fathi A, Azad-Fallah P, Ahmadi F. Effectiveness of marital enrichment program s on couples' marital satisfaction. J Clin Psycholy. 2011; 3(1): 27-37.

17. Blanchard VL, Hawkins AJ, Baldwin SA, Fawcett EB. Investigating the effects of marriage and relationship education on couples' communication skills: A meta-analytic study. J Fam Psychol. 2009; 23(2): 203-14.

18. Clark MS, Lemay EP, Graham SM, Pataki SP, Finkel EJ. Ways of giving benefits in marriage norm use, relationship satisfaction, and attachment-related variability. Psychol Sci. 2010; 21(7): 944-51.

19. Esmaeilpour K, khajeh V, NM. Predicting couples' marital satisfaction based on relationship beliefs and relationship skills. J Fam res. 2013; 9(1): 29-44.

20. Zarei F, Khakbaz H, Karami H. Determining the effectiveness of self-awareness skill training on reducing high-risk behaviors associated with the Opposite Sex Addict . J Res Addict. 2010; 4(15): 63-9. 
21. Moradpoor J, Miri M, Aliabadi S, Poorsadegh A. Effectiveness of training self-awareness and assertiveness skills on self-esteem and compatibility of mothers ofmentally retarded children. Modern care J. 2013; 10(1): 43-52.

22. Yilmaz T, Kalkan M. The effects of a premarital relationship enrichment program on relationship satisfaction. Educational Sciences: Theory and Practice. 2010; 10(3): 1911-20.

23. Danesh E. Improving marital adjustment levels of incompatible couples with the Islamic counselling. Psycholog Stud. 2010; 6(2): 167-186.

24. Baghiyan MJ, Pazhuhinia SH, Boroumand Rezazadeh Z. The effectiveness of empathy training program on improving relations between their personal and emotional adjustment of students with symptoms of ADHD. J School psychol. 2013; 3(2): 6-24.

25. Vaziri S, Lotfi Azimi A. The Effect of Empathy Training in Decreasing Adolescents Aggression. Iranian Psychologists. 2011;8(30):167-75.

26. Lovett BJ, Sheffield RA. Affective empathy deficits in aggressive children and adolescents: A critical review. Clin Psychol Rev. 2007; 27(1): 1-13.

27. Shahbazi S, Hazrati M, Moattari M, Heidari M. The Effect of Problem Solving Skills Training on Emotional Intelligence of Nursing Students of Shiraz (2008). Iran J Med Edu. 2012; 12(1): 67-76.

28. Mousavi Zadeh SA, Sohrabi F, Ahadi $H$. Comparative effectiveness of assertiveness and problem-solving skills on marital satisfaction of women student at Allameh Tabatabai University. Womens Stud. 2012; 10(2): 85-108 (Persion).

29. Murphy-Graham E. And when she comes home? Education and women's empowerment in intimate relationships. Int J Edu Dev. 2010; 30(3): 320-31.

30. Sahebalzamani M, Norouzinia R, Aliloo L, Rashidi A. Effect of self-expression training on promoting female high school students self-esteem and firmness. Urmia Med J. 2010; 21(1): 53-8.

31. Bahrami F, Moazedian A, Hosseini- Almaddani SA. The effectiveness of problem-solving and decisionmaking skills on redaction of positive attitudes in opium dependents. Q J of Res Addict. 2013; 7(25): 57-72.

32. Hadizadeh mghadam A, Tehrani $\mathrm{m}$. The relationship between the general styles of management decisions in public organizations. Government Management. 2010; 1(1): 133-8.

33. yousefi N, Bahgherian $M$. The investigation of the criteria of spouse selecting and marital burnout as forwarded variants in couples applicant for divorce and couples desirous of continuing the marital status. J Fam Counsel. 2012; 1(3): 284-301.

34. Mossalanejad L, Kargar MS. Mate selection criteria from the perspective of two groups of students of medical sciences in 1380 JAHROM. Teb va Tazkieh. 2006; 15(2-1): 32-7.

35. Khodayari Fard M, Shahabi R, Zardkhaneh SA. Religiosity and marital satisfaction. Procedia-Social and Behavioral Sciences. 2013; 82: 307-11.

36. Williams AJ. Enhancing marital happiness: The effects of religious attendance on infidelity, religious congruence, and spousal supportiveness: University of Utah; 2010.

37. Attari YA, Abbasi Sarcheshme A, Mehrabi Zadeh Honarmand M. Simple and multiple relationships religious attitude, optimism and attachment styles and marital satisfaction in married men students of Shahid Chamran University. J Educ Psychol, Shahid Chamran Univ 2006; 3(13): 93-110.

38. Sayadpour Z. Successful marriage: A study of marital satisfaction in student. Devlopmental Psychology. 2005; 1(2): 145-58.

39. Monjezi F, Shafiabadi A, Sodani M. Effectiveness of training communicative skills based on Islamic views on Married Couple’s Satisfaction. Knowledge and Research in Applied Psychology. 2012; 13(1): 3-10.

40. Buunk BP, Dijkstra P, Fetchenhauer D, Kenrick DT. Age and gender differences in mate selection criteria for various involvement levels. Personal Relationships. 2002; 9(3): 271-8.

41. Haghighizadeh M, Kararmi K, Soltani T. The criteria of spouse choosing in viewpoint of Ahwaz Jundishapur University of Medical Sciences students. Q J Health Sci. 2001; 2(2): 44-54.

42. Rahmani A, Merghati Khoei E, Sadeghi N, Allahgholi L. Relationship between Sexual pleasure and Marital Satisfaction. Iran J Nurs. 2011; 24(70): 82-90.

43. Khalatbari J, Ghorban Shiroudi S, Mahdiuon ZS. Influence of instruction of preparation programme for marriage on couple's communication beliefs. J Edu Psy. 2009; 1(1): 32-45. 
44. Pourmarzi D, Rimaz S, Merghati Khoei EA-S. Sexual and Reproductive Health Educational Needs in Engaged Couples in Tehran in 2010. Sexuality Research and Social Policy. 2014; 11(3): 225-32.

45. Shahhosseini Z, Hamzehgardeshi Z. Female adolescents' perspective about reproductive health education needs: a mixed methods study with explanatory sequential design. IJAMH. 2014; 26(1): 123-9.

46. Pourmarzi D, Rimaz S, Khoii M, Al-sadat E, Razi M, Shokoohi M. Comparative survey of youth's sexual and reproductive health educational needs in two stages before and after marriage, Tehran 2011. RJMS. 2013; 20(106): 30-9.

47. Mehrabi Zadeh Honarmand M, Hossein Pour M, Mehdizadeh L. The effectiveness of life skills training on increase of marital adjustment in 20-40 year-old married women. Journal of Learning and Teaching Studies. 2010; 2(1): 125-39.

48. Bolourian Z, Ganglu J. Evaluating sexual dysfunction and some related factors in women attending Sabzevar Health Care Centers. J Reprod Infertil. 2007; 48(2): 163-170.

49. Farnam F, Pakgohar M, Mir-mohammadali M. Effect of pre-marriage counseling on marital satisfaction of Iranian newlywed couples: a randomized controlled trial. Sexuality \& Culture. 2011; 15(2): 141-52.
50. Shams Mofaraheh Z, Shahsiah M, Mohebbi S, Tabaraee Y. The effect of marital counseling on sexual satisfaction of couples in Shiraz city. Health system research. 2009; 6(3): 417-24.

51. Samari AA, Lali Faz A. Efficacy of teaching life skills and social acceptance of family stress. The Q J Fund Men Health. 2005; 7(25): 47-55.

52. Shahhosseini Z, Abedian K. Iranian university students' perceived reproductive health needs. Int J Adolesc Med Health. 2014; 26(3): 339-44.

53. Fathi Ashtiani A, Ahmadi K. Study of successful and unsuccessful marriages among students. Daneshvar Raftar. 2003; 1(7): 9-16.

54. Aghajanian A. Some notes on divorce in Iran. J Marriage Fam. 1986; 48(4): 749-55.

55. Surra CA, Boelter JM. Dating and Mate Selection. In: Peterson GW, Bush KR editors Handbook of Marriage and the Family. New York: Springer; 2013. p. 211-32.

56. Aliakbari Dehkordi M. A comparative study of mate selection criteria of Ahwazi Young Girls. Daneshvar Raftar. 2007; 14(25): 75-83.

57. Abedian K, Shahhosseini Z. University students' point of views to facilitators and barriers to sexual and reproductive health services. Int J Adolesc Med Health. 2014; 26(3): 387-92. 